\title{
Benchmarking: een methode om te leren
}

Drs. R.M. de Haan en Dr. K.R.E. Huizingh

\section{Inleiding}

'Als je je vijand kent en je kent jezelf, hoef je niet bang te zijn voor het resultaat van honderd gevechten , dit had een uitspraak kunnen zijn van een managementgoeroe om benchmarking aan te prijzen. In werkelijkheid dateert de uitdrukking al van voor onze jaartelling en is afkomstig van de Chinese generaal Sun Tzu (Camp, 1992). Aan het einde van de $20^{\circ}$ eeuw is de parallel met benchmarking duidelijk: ook bij benchmarking wordt uitvoerig een andere organisatie bestudeerd, een concurrent of een onderneming die op een bepaald terrein excellent is, met als doel hiervan te leren en beter opgewassen te zijn tegen de gevechten die hedendaagse organisaties op turbulente en mondiale markten hebben te leveren.

Traditioneel wordt benchmarking als methode vaak in verband gebracht met de Total Quality Management (TQM) filosofie. TQM is gericht op het realiseren van continue verbeteringen, alsmede een organisatorisch klimaat om dit mogelijk te maken (Besterfield, 1995; Pegels, 1995; Kanji en Asher, 1996). Binnen TQM kan benchmarking als methode worden gebruikt om een antwoord te vinden op de vraag welke verbeteringen mogelijk zijn en hoe deze kunnen worden gerealiseerd. Nieuwer is de aandacht voor benchmarking in relatie tot actuele thema's zoals 'kerncompetenties' (Hamel en Prahalad, 1994) en 'lerende organisaties' (Senge, 1990, 1994), zie bijvoorbeeld publicaties van Zairi en Leonard (1994) en Schramade en Tjepkema (1993). Door de nadruk te leggen op de eigen competenties en steeds vernieuwende kennis tracht een organisatie de (gepercipieerde) klantwaarde van een product of dienst te verhogen. Centraal staat een continu leerproces, gericht op het ontdekken en vergaren van impliciete kennis binnen en buiten de eigen organisatie (Hamel en Heene, 1994). Benchmarking kan worden gebruikt om deze kennis te identificeren.

Met dit artikel willen we inzicht geven in benchmarking als methode waarmee organisaties kunnen leren van andere organisaties. Aan de orde komen vragen als: wat is benchmarking, hoe verloopt benchmarking, welke voor-en nadelen kent de methode en welke varianten worden onderscheiden? In de eerste paragraaf zullen we het begrip 'benchmarking' definiëren en aandacht besteden aan de historische achtergronden van benchmarking. Paragraaf 2 gaat in op de wijze waarop benchmarking wordt uitgevoerd: het benchmarkingproces. Vervolgens volgt in paragraaf 3 een overzicht van de belangrijkste vooren nadelen van benchmarking en in aansluiting hierop worden in paragraaf 4 een aantal succesbepalende factoren geïdentificeerd. Paragraaf 5 behandelt een typologie van benchmarking, om duidelijk te maken dat het concept veel rijker is

Drs. R.M. de Haan is afgestudeerd op het onderwerp Databasebenchmarking bij de vakgroep Bedrijfseconomie aan de Rijksuniversiteit Groningen Momenteel is hij als organisatie-adviseur werkzaam bij Andersen Consulting en houdt zich bezig met procesherontwerp en -optimalisatie binnen de financiële dienstverlening.

Dr. K.R.E. Huizingh is universitair docent bij de vakgroep Bedrijfseconomie aan de Rijksuniversiteit Groningen. In juni 1992 promoveerde hij op onderzoek getiteld 'Marketing Informatiesystemen: perspectief voor een ontwikkelingspad'. 
dan alleen vergelijking met concurrenten. In paragraaf 6 staan we stil bij een relatief nieuwe, exploratieve vorm van benchmarking waaraan recentelijk in toenemende mate aandacht wordt besteed, namelijk database-benchmarking. We eindigen het artikel met een aantal conclusies omtrent de bruikbaarheid van benchmarking als methode om het leren door en in organisaties te verbeteren.

\section{Benchmarking}

Op de vraag wat benchmarking precies inhoudt zijn vele antwoorden te vinden. Het American Productivity and Quality Centre (APQC), oprichter van het International Benchmarking Clearinghouse (IBC). benadrukt in haar definitie de voorwaarde voor 'leren': de bereidheid om niet alleen kritisch naar anderen te kijken maar vooral ook naar jezelf:

Benchmarking is the practice of being humble enough to admit that someone else is better at something, and heing wise enough to learn how to match and even surpass them at it. (Rolstaadas et al., 1995)

Een andere veel geciteerde definitie is die van David T. Kearns, CEO van Xerox Corporation. Xerox staat wereldwijd hoog aangeschreven om haar pioniersrol op het gebied van benchmarking. Zijn definitie benadrukt de inhoud van benchmarking:

Benchmarking is het vortdurende proces ran het meten van producten, diensten en werkwijzen in vergelijking met de sterkste concurrenten of met die bedrijuen die erkend worden als marktleiders (Camp, 1992).

Manco aan de definitie van Kearns is dat geen expliciete aandacht is geschonken aan het doel van benchmarking. Spendolini ( 1992) daarentegen besteedt in zijn definitie aandacht aan de verschillende kenmerkende elementen van benchmarking. Op basis van uitgebreid empirisch onderzoek, geeft hij de volgende definitie:

Benchmarking is a continuous, systematic, process for evaluating the products, services, and work processes of organizations that are recognized as representing best practices for the purpose of organizational improvement.
Spendolini onderscheidt in deze definitie negen belangrijke elementen van benchmarking: benchmarking betreft (1) continu meten om trends en ontwikkelingen te signaleren, (2) gebaseerd op een gestructureerde aanpak, (3) die bestaat uit een reeks van opeenvolgende activiteiten (een proces), waarbij (4) niet alleen wordt geleerd door te meten (kwantitatief) maar ook door te onderzoeken (kwalitatief). Benchmarking (5) beperkt zich niet tot één bepaalde soort activiteiten of (6) organisaties (bijvoorbeeld alleen concurrenten), maar (7) in een vooronderzoek worden de geschikte benchmarkingpartners bepaald en wel ( 8 ) zij die excelleren op het betreffende onderzoeksgebied. Het negende en laatste kenmerk benadrukı dat leren actiegericht moet zijn, ofwel leren moet ergens toe leiden.

Benchmarking in de zin van 'leren door af te kijken" stamt uiteraard al uit de oudheid. De kracht van benchmarking is echter dat het meer is dan kopiëren. Een treffend en klassiek voorbeeld is de introductie door Ford van de lopende band, die in 1916 volledig operationeel werd (Lucertini et al., 1995). Ford werd geïnspireerd door een bezoek in 1911 aan een groot abattoir in Chicago. De organisatie van de werkprocessen in het abattoir bestond uit een opeenvolging van gespecialiseerde werkcellen ("flow shop"). Met succes werd dit principe vervolgens toegepast in de autofabrieken van Ford waardoor de mogelijkheden ontstonden voor een snellere en goedkopere productie.

Van veel recentere datum is de werkelijke professionalisering van benchmarking. In 1979 besloot Xerox, gedwongen door de gevolgen van hevige Japanse concurrentie, te onderzoeken wat voor prestaties werden geleverd door de concurrentie en vooral ook hoe men dat voor elkaar kreeg (Camp. 1992). De beste concurrenten werden geselecteerd waarna uitgebreid studie werd gemaakt van hun producten en processen. Deze activiteiten hebben uiteindelijk geleid tot de wederopstanding van Xerox in de jaren tachtig. Tegelijk maakte dit van Xerox een van meest toonaangevende organisaties op het gebied van benchmarking. Camp (1992) beschreef op gedetailleerde wijze zijn benchmarking-ervaringen bij Xerox en jarenlang vormde dit boek, naast enige artikelen. de belangrijkste literatuur op dit gebied. In de afgelopen jaren is hierin verandering gekomen, mede als gevolg van de belangrijke stimulans die is uitgegaan van het instellen van de Malcolm Baldrige National Quality Award in 1987 
(Czuchry et al., 1995). De Balridge Award wordt uitgereikt aan organisaties die uitmunten op het gebied van kwaliteitsmanagement. Van de winnaars wordt verwacht dat zij hun succesvolle kwaliteitstrategieën en informatie delen met andere organisaties. Inmiddels hebben de 17 Baldrige-winnaars van voor 1993 hun kennis en ervaring gedeeld met honderdduizenden andere organisaties (Czuchry et al., 1995). Een deel van de strenge beoordelingscriteria voor de Balridge Award heeft betrekking op benchmarkingprocessen en procedures die dienen om trenddata te verzamelen en vergelijkingen uit te voeren. Voor organisaties die niet meedingen naar de $A$ ward dienen de Balridge-criteria als een raamwerk voor zelfevaluatie, planning en training.

In de Verenigde Staten blijkt het toegenomen belang dat organisaties hechten aan benchmarkingactiviteiten uit een in 1993 uitgevoerd onderzoek van het International Benchmarking Clearinghouse (Czuchry et al., 1995). 75\% van de ondervraagde bedrijven bleek van plan tot 1998 de bestaande benchmarkingactiviteiten significant uit te breiden. Ongeveer $21 \%$ wilde slechts komen tot een geringe expansie en slechts $4 \%$ zag geen toename. In Nederland werd onderzoek verricht door het NIPO. Er bleek een met de Verenigde Staten vergelijkbare interesse te bestaan: maar liefst $72 \%$ van de top- 1000 bedrijven claimt aan benchmarking te doen (NIPO, 1994). Van de top1000 zegt $44 \%$ op gestructureerde wijze aan benchmarking te doen. Voor de toekomst verwacht $58 \%$ van de ondervraagde Nederlandse bedrijven dat het gebruik van benchmarking zal toenemen. $41 \%$ verwacht een stabilisatie. Winkler (1996) geeft een niet uitputtend overzicht van de activiteiten van adviesbureaus die in Nederland benchmarkingdiensten aanbieden.

\section{Het Benchmarkingproces}

Een benchmarkingproces gaat verder dan alleen het vinden van een referentiepunt om vervolgens vergelijkingen te maken. De kern van benchmarking bestaat uit een drietal activiteiten: meten, analyseren en verbeteren. Allereerst stelt men de relatieve prestaties vast: wat is de prestatie? Vervolgens wordt door middel van een analyse getracht de onderliggende werkmethoden te bepalen: hoe komt men tot deze prestatie? Het beantwoorden van de wat-en hoe-vraag is vaak een iteratief proces. De derde stap start een veranderingstraject om de beste van de gevonden werkmethoden te implementeren in de eigen organisatie. Benchmarking gaat nadrukkelijk verder dan leren in de zin van kennis verzamelen, ook het toepassen van deze kennis behoort tot het benchmarkingproces. Benchmarking is dan ook pas geslaagd als de verzamelde kennis succesvol is toegepast in de eigen organisatie. In dit kader dient een onderscheid te worden gemaakt tussen kennis van 'werkmethoden' en kennis van 'mogelijkheden' (Camp, 1992). De kennis van 'mogelijkheden' in de vorm van metingen beperkt zich tot het kwantificeren van het (positieve of negatieve) effect van een werkmethode. Daarentegen malakt de kennis van "werkmethoden" het mogelijk een geconstateerde prestatiekloof te dichten.

Er bestaan verschillende methodologieën voor het uitvoeren van een benchmarkingproces (Czuchry et al., 1995). De meest bekende is de methodologie van Xerox (figuur 1) die bestaat uit een tien-stappenplan voor het doorlopen van het benchmarkingproces (Camp, 1992). In een vergelijking tussen een aantal aanpakken concluderen Zairi en Leonard (1994) dat het stappenplan van Xerox het meest compleet is. De hierboven onderscheiden 'wat' en 'hoe' vraag beslaat de eerste vijf stappen. de resterende stappen zijn alle gewijd aan het implementeren van het geleerde. Dit onderstreept opnieuw het belang van toepassing van het geleerde boven alleen het verzamelen van kennis.

Figuur 1: Het tien-stappenplan van Benchmarking van Xerox (Camp, 1992)

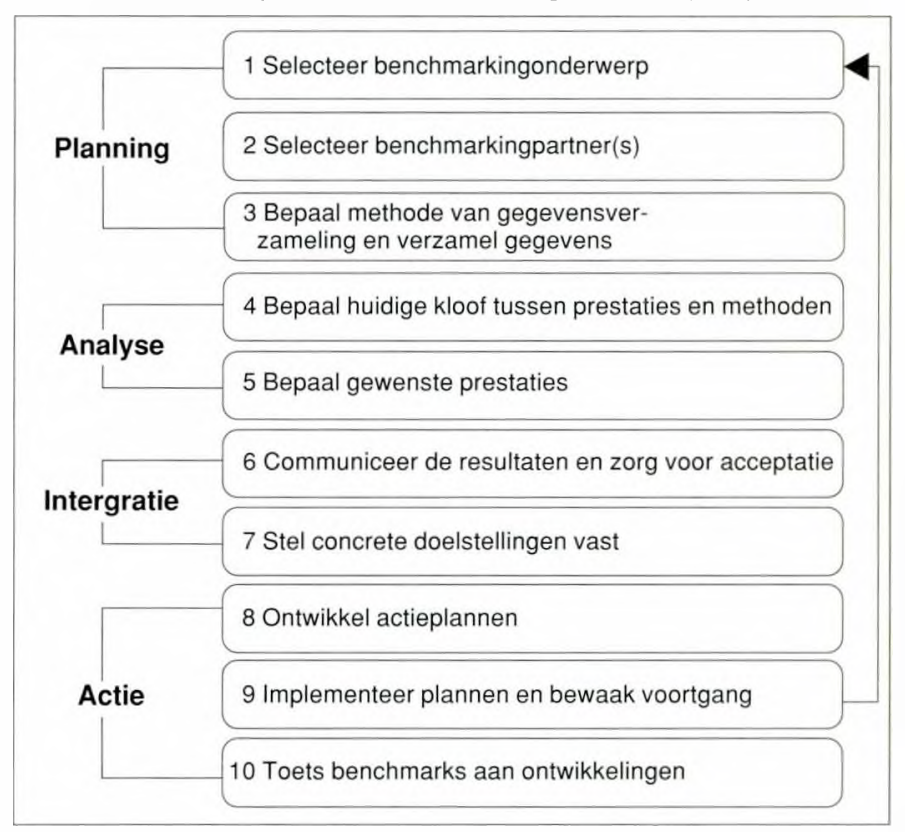




\section{Voor-en nadelen benchmarking}

Nu inzicht is gegeven in het doel en het proces van benchmarking, willen we nader ingaan op de sterkten en zwakten van benchmarking. In de volgende paragraal komen factoren aan de orde die

Tabel 1 Een overzicht van voordelen cen nadelen van benchmarking

\begin{tabular}{|c|c|}
\hline loordelen & Nadelen \\
\hline $\begin{array}{l}\text { 1 Slimuleren en benulten van een } \\
\text { leerhouding }\end{array}$ & I Groot tijdstiesilan \\
\hline 2 Motiveren werknemers & 2 Veel mankiacht \\
\hline $\begin{array}{l}3 \text { Verkijgen van externe focus on de } \\
\text { cigen positie te bepalen }\end{array}$ & 3 Kostbial \\
\hline 4 Bicden vin een objectiel referentiepunt & + Niet verzekerd valn resultall \\
\hline $\begin{array}{l}5 \text { Bijdrage alan stratcgicvorming } \\
\text { en -implementatie }\end{array}$ & \\
\hline $\begin{array}{l}6 \text { Valststellen van ambilieuze miar } \\
\text { hatalbare doelstellingen }\end{array}$ & \\
\hline $\begin{array}{l}7 \text { Vinden en integreren valn heste } \\
\text { werkuijzen in ejgen organisatlie }\end{array}$ & \\
\hline
\end{tabular}

invloed hebben op het welslagen van een benchmarkingproject, in deze paragraaf staan we stil bij de algemene voordelen en nadelen van benchmarking. Hieronder worden beide categoricen besproken, in tabel 1 stalat een overzicht van deze punten.

\section{Voordelen}

De Geus (1988) stelt dat het vermogen om sneller te leren dan de concurrentie voor een organisatie het enige houdbare concurrentievoordeel is. De kracht van benchmarking is dat het kan fungeren als katalysator voor het leerproces binnen een organisatie en een "continue bereidheid tot leren verlangl (Schramade en Tjepkema, 1993). De werknemers zelf doorlopen een leer- en verbeteringsproces wat vervolgens een positieve invloed heeft op de motivatie (Camp. 1992; De Vriend en Timmerman. 1995; Senge. 1994). Het door de gezamenlijke organisatie benutten van de leerhouding in de vorm van concrete, walardevolle verbeteringen staat hierbij voorop (Rolstandas et al., 1995; Spendolini, 1992; Schramade en Tjepkema, 1993). Op deze wijze draagt benchmarking bij aan het ontwikkelen en in stand houden van een lerende organisatie (Pedler. Burgoyne en Boydell. 1991 ).

Een ander voordeel is dat gedurende het benchmarkingproces objectieve externe gegevens worden gegenereerd waarmee vergelijkingen kunnen plaatsvinden (Rolstaadas et al., 1995; Camp, 1992; Spendolini, 1992). Hierdoor ontstaat een realistisch beeld van de markt(positie), de kritische succesfactoren en de sterkten en zwakten van de onderneming (Camp, 1992). Tevens kunnen hiermee perspectiefrijke verbetergebieden en prioriteiten worden vastgesteld met als doel de waarde voor de klanten te vergroten en niel-waardetoevoegende activiteiten te elimineren (Rolstaadas et al.. 1995; De Vriend en Timmerman, 1995). Benchmarking moet organisaties hiermee in statat stellen sneller te anticiperen op veranderingen (Senge, 1994).

Een evident voordeel van benchmarking is dat de bewezen werkmethoden en technologieën een uitstekende bron vormen voor het opdoen van nieuwe ideëen (Camp, 1992; Spendolini, 1992). Wanneer een organisatie in staat is deze ideëen op een creatieve wijze in concrete toepassingen te vertalen, kunnen zowel continue als sprongsgewijze verbeteringen worden gerealiseerd.

Ten slotte draagt het formuleren van onbetwistbare korte- en lange-termijndoclstellingen bij aan het vormen en implementeren van de strategie (De Vriend en Timmerman, 1995; Spendolini, 1992). De, door anderen. bewezen prestaties vormen het uitgangspunt voor het opstellen van geloof waardige streefwaarden voor de eigen organisatie (De Vriend en Timmerman. 1995; Rolstaadas et al.. 1995: Spendolini, 1992).

\section{Nadelen}

Het belangrijkste nadeel van benchmarking is hel grote tijdsbeslag dal wordt gelegd op een organisatie (Lewis en Naim. 1995: Shetty. 1993; Van de Voort en De Vries, 1993). De methode is niet 'quick and dirty', maar vereist een gedegen voorbereiding bij clke stap in het proces (Spendolini, 1992). Een succesvolle uitvoering vereist dat relatief veel menskracht beschikbaar is (Spendolini, 1992: Lewis en Naim. 1995: Shetty. 1993; Van de Voort en De Vries, 1993). Het gevolg is dan ook dat benchmarking al snel een kostbare aangelegenheid vormt (Spendolini. 1992; Lewis en Naim. 1995; Shetty. 1993: Van de Voort en De Vries. 1993). Onderzoek in de Verenigde Staten door het International Benchmarking Clearinghouse heeft uitgewezen dat per participant de gemiddelde kosten van een benchmarkingexcercitie liggen rond de $\$ 60.000$ (Fitz-enz, 1994). Het zorgvuldig alwegen van de kosten, voordat met benchmarking wordt gestart, is vooral ook belangrijk omdat een 
bedrijf niet is verzekerd van succes. Het kan blijken dat het succes van een excellente onderneming om wat voor reden dan ook niet is over te nemen in de eigen organisatie. Hoewel een dergelijke uitkomst uiteraard zo vroeg mogelijk dient te worden opgemerkt. valt niet uit te sluiten dat dit pas na verloop van tijd aan het licht komt.

\section{Succesbepalende factoren}

In de praktijk blijkt het toepassen van benchmarking nog wel eens te leiden tot teleurstellingen. Een bekende valkuil is dat organisaties de neiging hebben om te snel met benchmarking te starten. Men slaat direct aan het verzamelen van informatie en vergeet een goede voorbereiding (onder andere het bepalen van een duidelijk doel en het begrijpen en documenteren van processen). Organisaties starten simpelweg met het analyseren van een proces omdat het mogelijk is en onderschatten de inspanningen die gemoeid zijn met benchmarking. Achteraf blijkt het onderwerp te groot, is het onderzoek te gedetailleerd uitgevoerd, of zijn er onrealistische verwachtingen gewekt (Fitz-enz, 1994). Het resultaat is dat de aanbevelingen niet realiseerbaar zijn of leiden tot onvoldoende verbetering (Spendolini, 1992). Onder meer de volgende factoren hebben invloed op de mate waarin benchmarking succesvol is (deels gebaseerd op Rolstaadas et al., 1995):

- methodologische aanpak;

- structurele factoren;

- culturele factoren;

- procesbenadering:

- prioriteitsstelling:

- integratie in planningsproces;

- integratie in het bestaande verbeteringsproces.

\section{Methodologische aampak}

Benchmarking hoeft geen moeilijke opgave te zijn zolang het gestructureerd plaatsvindt. Spendolini (1992) noemt de volgende twee belangrijke voordelen. Ten eerste ontstaat op deze wijze een raamwerk voor het uitvoeren van de verschillende noodzakelijke activiteiten. Daarnaast draait benchmarking om het opdoen van kennis, met name door het uitwisselen van informatie tussen partijen die voorheen nauwelijks of geen contact met elkaar hadden. Een structuur, bijvoorbeeld in de vorm van een stappenplan, helpt de effectiviteit te bevorderen door te komen tot een gemeenschappelijke taal.

\section{Structurele factoren}

Benchmarking veronderstelt dat in een organisatie een aantal structurele zaken geregeld zijn. Van de Voort en De Vries (1993) spreken in dit kader van 'een institutionalisatie van benchmarking'. Als factoren kunnen worden genoemd:

- financiële middelen; benodigd voor onder meer huisvesting, pc's, literatuur en administratieve ondersteuning (Spendolini, 1992);

- $\quad$ tijd; om alle benchmarkingtaken uit te voeren (Lewis en Naim, 1995);

- proceskennis; in het team dient iemand te zijn opgenomen met kennis van het proces dat onderwerp van studie is. Daarnaast dient het proces goed gedocumenteerd te zijn (DeToro, 1995);

- benchmarkingkennis; uit onderzoek blijkt dat -...if the technique and the business itself have not been investigated thoroughly, then the results may have a negative repercussion on the long-term effectiveness of the company' (Lewis en Naim, 1995). Men moet in staat zijn het benchmarkingproces van begin tot einde te begrijpen (Pryor en Katz, 1993). Aandacht voor training en opleiding op het gebied van benchmarking is dan ook gewenst ( $V$ an de Voort en De Vries, 1993).

\section{Culturele factoren}

Benchmarking is gericht op het realiseren van verbeteringen. De benodigde veranderingen vinden over het algemeen plaats in de structuur èn in de cultuur van een organisatie. Een organisatie dient daarom vooral ook 'rijp' te zijn voor benchmarking (Van de Voort en De Vries, 1993). Voorwaarden op het culturele vlak zijn:

- ambities; zonder ambities gebeurt er niets;

- steun van het (top)management; sponsorship van de (top)leiding geeft aan dat men benchmarking serieus neemt;

- veranderingshereidheid; benchmarking betekent de wil hebben om te veranderen (Goldwasser, 1995), bestaat er weerstand dan zal deze eerst dienen te worden weggenomen (Pryor en Katz, 1993);

- participatie werknemers; benchmarking is een decentralal proces (Weber, 1995). Het betrekken van werknemers bij benchmarking-activiteiten helpt (potentiele) weerstand te overkomen en geeft werknemers inzicht in de noodzaak en mogelijkheden voor veranderingen (Goldwasser, 1995); 
- bereidheid informatie te delen; dit geldt zowel intern als extern en vercist een continue communicatie door de hele organisatie heen (Pryor en Katz, 1993). Openheid helpt een breder begrip te $k$ weken voor de potentiële mogelijkheden en voordelen van veranderingen (Goldwasser. 1995).

\section{Procesbenadering}

Het doel van een benchnuarkingonderzock is globilal aan te duiden met het optimaliseren van interne efficiëntie of externe effectiviteit" (De Vries. 1995). Een procesbenadering biedt de mogelijkheid beide tegelijkertijd te realiseren (Garvin, 1995).

Zowel een goed hegrip en bewustzijn valn, als inzicht in de rol van processen in een organisatie zijn voorwatarden om deze doelstellingen te verwezenlijken. Dat wil zeggen: eerst de cigen processen leren kennen en in kaart brengen en dan die van de benchmarkingpartner(s) (DeToro. 1995).

\section{Prioriteitsstelling}

Benchmarking kost een aanzienlijke hoeveelheid tijd en geld en daarom dient vooraf een selectie valn het onderzocksonderwerp plats te vinden op basis van (kritische) behoefien. Kritische succesfactoren helpen te bepalen welk onderwerp de meeste impact heeft op de resultaten van een organisatie (Rolstaladas el al., 1995). Aan de hand hiervan wordt een prioriteitsstelling opgesteld van onderwerpen die het meest geschikt zijn om te benchmarken (DeToro. 1995).

\section{Integratic in planningsproces}

Een benchmarkingonderzoek zonder richting leidt tot een minder efficiënt en effectief gebruik van beschikbare schaarse middelen. Pryor en Katz (1993) stellen daarom dat "... besluitvorming het uitgangspunt dient te zijn voor elk benchmarkingonderzoek'. Tezamen mel de gevonden koersalternatieven dienen de bewezen prestaties als input voor het planningsproces. Aan de output-zijde leidt benchmarking tot implementatie van de opgestelde plannen (Van de Voorl en De Vries, 1994).

\section{Integratie in het bestande leer-e'n verbeteringsproces}

Benchmarking is een methode en dient als zodanig in een groter geheel te worden geplatst.
Vaunuit het planningsproces van een organisatic dient benchmarking een plaats te krijgen in het bestaande kader voor leer-en verbeteractiviteiten (Rolstaadas ct al.. 1995). In de praktijk betekent dit valak een ontwikkeling in de richting van een lerende organisattie en een inpassing in. en af stemming op het scala alun Total Quality Management-activiteiten. In dit kader levert de benchmarking-methode een actieve bijdrage aan de bestaande leer- en verbeteringsprocessen in cen organisatie (Zairi en Leonard. 1994: Van de Voort en De Vries. 1994).

\section{Typologie benchmarking}

Zoals met zoveel complexe verschijnselen kunnen we ook bij benchmarking vanuit verschillende invalshoeken tot verschillende indelingen van soorten benchmarking komen. In de literatuur worden hierbij onder meer de volgende dimensies gebruikl: onderwerp. niveau en partnerkeuze ( $V$ an de Voorl en De Vries, 1994). Elk van deze indelingen zullen we korl bespreken.

\section{Onderwerp}

Als onderwerp van benchmarking-sludies zijn uiteenlopende zaken atan te geven. Spendolini (1992) noemt strategie of planningsproces. producten en diensten, werkprocessen, ondersteunende functies, prestaties van de organisatie (zoals kosten. opbrengsten. productie en kwaliteit).

\section{Niveall}

Clayton en Luchs (1994) onderscheiden twee lundamentele niveaus voor benchmarking, namelijk een micro- en een macroniveau. Benchmarking op micronive'an heefi betrekking op de vergelijking van specificke functies of processen ("business process benchmarks"). Hierbij deelı men de activiteiten op in componenten waarna de belangrijkste processen worden geïdentificeerd en vergeleken met op dal terrein excellerende organisaties. Op maroniveau houdt benchmarking een vergelijking in van prestaties die de uitkomsten vormen van meerdere processen en werkmethoden ("business unit benchmarks").

Een ander onderscheid in niveaus is de indeling in strategische, operationele en procesbenchmarking (Clayton en Luchs. 1994). In het geval van strategische benchmarking gatat het om een becld te krijgen van de markipositie of de 
mogelijkheid een specifieke toegevoegde walarde te realiseren. Shetty (1993) noemt in dit verband het identificeren van succesvolle elementen uit strategieën van succesvolle organnisaties. Ook kunnen de core competences van een organisatie onderwerp van een benchmarkingonderzock zijn. bijvoorbeeld om beter in stalt te zijn product/ markicombinaties te ontwikkelen (Waalewijn en Kamp. 1994).

Met behulp van proceshenclimarking worden de (werk) processen verder verbcterd en geoptimaliseerd. Pryor en Katz (1993) spreken van 'kostengerichte benchmarking' met aandacht voor de productieproces-technische factoren. Deze vorm is gericht op een of enkele functies. processen of activiteiten.

Operationele benchmarking ligt tussen strategische en procesbenchmarking in. Uitgaande van de strategie is het doel tekortkomingen van processen aan het licht te brengen. Deze maatstaven definiëren niet de strategie sec, maar geven indicaties op basis waarvan men prioriteiten kan aangeven bij het verbeteren van processen. In het verleden vonden vergelijkingen voornamelijk plaats in termen van kosten of fysieke eenheden. Tegenwoordig worden steeds vaker vergelijkingen gemalakt in termen van klanttevredenheid, zoals kwaliteit, betrouwbaarheid, service, prijsstelling en levertijd. Pryor en Kat7. (1993) noemen dit 'klantgerichte benchmarking'.

\section{Partmerkenze}

Tijdens de zoektocht naar een geschikte partner in de interne en externe omgeving kan men dicht bij de eigen organisatie blijven of zich verder daarvanweg begeven. Op deze wijze onderscheidt Camp (1992) de volgende typen benchmarking: interne-, concurrerende-, functionele- en generieke benchmarking.

Voor grote organisaties bestaat de mogelijkheid eerst intern ervaring op te doen met benchmarking. Interne benchmarking helpt de meest succesvolle werk wijzen binnen de eigen organisatie te achterhalen (zie tabel 2). Als gevolg van geografische en/ of organisationele verschillen kunnen de efficiency en effectiviteit van afdelingen, business units of vestigingen uiteen lopen. Zo bleken tijdens een onderzoek bij een universite it in Nederland naar het functioneren van de financiële administratie er significante verschillen in efficiency te bestaan tussen faculteiten. Doordat interne benchmarking inzicht geeft in, en begrip van de eigen interne organisatie geldt het daarom als een goed startpunt voor verder (exlern) onderzoek.

Tabel 2: De voordelen en nadelen van interne benchmarking

\begin{tabular}{|c|c|}
\hline Voordelen & Nadel'n \\
\hline $\begin{array}{l}\text { - Eenvoudige realisatie verheteringen } \\
\text { - Verkrijgen goed begrip eigen interne } \\
\text { organisatie: startpunt verder (extern) } \\
\text { onderzoek } \\
\text { - Definiëren interne standiatrden } \\
\text { - Stimuleert interne communicattie } \\
\text { - Informatie is gemakkelijk te verkrijgen } \\
\text { - Hoeti relatief weinig lijol te nemen } \\
\text { - Gemeenschappelijke 'taal' }\end{array}$ & $\begin{array}{l}\text { - Beperkie locus } \\
\text { - Soms even gecompliceerd en } \\
\text { kostbilar als extern onderzoek } \\
\text { - Gevalar van verlekening } \\
\text { - 'Ratam' onvoldoende open: } \\
\text { geen 'beste' werkwijzen } \\
\text { - Succes ondergrabti recht- } \\
\text { vaardiging extern onderzoek }\end{array}$ \\
\hline
\end{tabular}

Bij benchmarking ligt het voor de hand buiten de eigen organisatie te kijken en vergelijkingen te maken met directe. indirecte of potentiële concurrenten: concurrerende henchmarking (zie tabel 3). Een mogelijk bezwalar van interne benchmarking is namelijk de beperkte focus, welke het gevaar van vertekening niet ondenkbeeldig maakt. Daarbij bestaat de kans dat slechts incidentele verbeteringen worden gerealiseerd. Om die reden werden tijdens het onderzoek bij de eerder genoemde universiteit vergelijkingen gemaakt met andere universiteiten en onderwijsinstellingen. De walarde van de intern gevonden efficieny-prestaties kon daarna beter worden ingeschat.

Tabel 3: De vordelen en nadelen van concurrerende benchmarking

\begin{tabular}{|c|c|}
\hline liondelen & Nadelen \\
\hline $\begin{array}{l}\text { - Direct relevante informittie voor } \\
\text { resultalten van organisatie } \\
\text { - Verkrijgen inzicht in positic op } \\
\text { de mark! } \\
\text { - Vergelijkbare producten, lechnolo- } \\
\text { gieèn en omgevingsinvloceden } \\
\text { - Mogelijke uitwisseling reeds verricht } \\
\text { benchmarkingonderzock }\end{array}$ & $\begin{array}{l}\text { - De sterkste concurrent hoeft niel } \\
\text { gebruik te miken van de beste } \\
\text { werkwijzen } \\
\text { - Zonder meer alinnemen } \\
\text { vergelijkbaitheid } \\
\text { - Informaticverzameling hij con- } \\
\text { currenten ligl gevoelig: mogelijk } \\
\text { juridische complicalies } \\
\text { - Weerstand tegen veranderingen } \\
\text { die zijn gebaseerd op werkuijzen } \\
\text { concurrenten ( not-invented-here } \\
\text {-syndroom) }\end{array}$ \\
\hline
\end{tabular}

Beperkt men zich bij het maken van vergelijkingen niet alleen tot de eigen branche, maar zoekt men marktleiders op functionele gebieden (zoals 
bijvoorbeeld met betrekking tot de efficiency en effectiviteit van de financiële administratie) dan spreken we van functionele benchmarking (zie tabel 4). Van belang is of de gevonden organisaties door dezelfde klanteneisen worden gedreven. In het voorbeeld van de eerdergenoemde universiteit werden vergelijkingen gemaakt met de financiële administratie van organisaties buiten het onderwijs, zoals een verzekerings- en een luchtvaartmaatschappij, een telecommunicatiebedrijf en een bank.

Tabel 4: De voordelen en nadelen van functionele benchmarking

\begin{tabular}{|l|l|}
\hline Voordelen & Nadelen \\
\hline $\begin{array}{l}\text { - Gericht op innoverend toepassen ge- } \\
\text { vonden beste werkwijzen in eigen } \\
\text { organisatie }\end{array}$ & $\begin{array}{l}\text { Minder goed vergelijkbaar door } \\
\text { verschillen in interne en } \\
\text { exteme omgeving }\end{array}$ \\
$\begin{array}{l}\text { Natuurlijke belangstelling voor elders } \\
\text { loegepaste werkwijzen: hogere accep- }\end{array}$ & $\begin{array}{l}\text { Relatief meer tijd benodigd } \\
\text { voor onder andere het vinden } \\
\text { tatiegraad werkwijzen buiten eigen } \\
\text { branche (doorbreken 'not-invented- } \\
\text { vere'-syndroom) }\end{array}$ \\
$\begin{array}{l}\text { - Kans op sprongsgewijze verbeteringen } \\
\text { - Overdraigbare werkwijzen en techno- } \\
\text { logieën }\end{array}$ & \\
- Ontwikkeling professionele netwerken & \\
\hline
\end{tabular}

De laatste vorm van benchmarking lijkt sterk op functionele benchmarking, maar gaat nog een stapje verder. Sommige processen zijn namelijk in essentie gelijk, ongeacht waar ze worden toegepast. Een voorbeeld is het factureringsproces binnen een financiële administratie. Deze vorm van benchmarking overschrijdt niet alleen de eigen branche, maar ook het eigen vakgebied. Generieke benchmarking biedt daarom de grootste kans op het realiseren van sprongsgewijze verbeteringen (zie tabel 5). Het benchmarkingonderzoek aan de universiteit vond plaats op basis van vergelijkingen tussen prestaties in standaard te onderscheiden processen binnen de financiële administratie, zoals het factureringsproces.

Tabel 5: De voordelen en nadelen van generieke benchmarking

\begin{tabular}{|l|l|}
\hline Voordelen & Nadelen \\
\hline $\begin{array}{l}\text { - Ontdekken beste werkwijzen en } \\
\text { technologieën buiten eigen vakgebied }\end{array}$ & $\begin{array}{l}\text { Meer tijd benodigd voor onder } \\
\text { andere het vinden van een } \\
\text { geschikte partner en bepalen } \\
\text { van generieke processen }\end{array}$ \\
$\begin{array}{l}\text { - Nerkwijzen soms moeilijk } \\
\text { overdraagbalar naar andere } \\
\text { toegepaliste werkwijzen; }\end{array}$ & $\begin{array}{l}\text { omgevingen } \\
\text { - Hoge potentie voor ontdekken innovaties } \\
\text { - Hogere acceptatiegraad werkwijzen } \\
\text { buiten eigen branche; doorbreken } \\
\text { 'not-invented-here'-syndroom }\end{array}$ \\
\hline
\end{tabular}

\section{Database-benchmarking}

Ondanks de toegenomen aandacht voor benchmarking gaan organisaties vaak schoorvoetend mee in de eerste initiatieven op dit terrein. Belangrijke obstakels voor de verdere verspreiding van benchmarking zijn de onzekerheid over de noodzakelijke kosten en tijdsinspanningen aan de ene kant en de te verwachten opbrengsten aan de andere kant. Dit weerhoudt organisaties ervan over te gaan tot het zelfstandig uitvoeren van een benchmarkingstudie met een interne of externe partner. De geschetste problematiek heeft geleid tot het ontstaan van een nieuwe vorm van benchmarking, namelijk database-benchmarking (Zairi en Hutton, 1995). Het gaat bij databasebenchmarking om het vergelijken van prestaties en onderliggende werkmethoden van een organisatie met in een database opgeslagen gegevens van andere organisaties. Het doel is inzicht te krijgen in de kansen voor substantiële leer- en verbeteringsactiviteiten.

Database-benchmarking is ontstaan in de Verenigde Staten waar grote adviesorganisaties en stichtingen zich zijn gaan bezighouden met het opzetten, vullen en toegankelijk maken van databases met benchmarkinggegevens. Een goed voorbeeld is het reeds eerder genoemde International Benchmarking Clearinghouse (IBC), een benchmarkingnetwerk van zo'n 100 organisaties. Daarnaast heeft ook PIMS (Profit Impact of Market Strategy) grote hoeveelheden benchmarkinggegevens tot haar beschikking (Buzzell en Gale, 1987). In Nederland zijn recentelijk door adviesorganisaties initiatieven genomen voor het opzetten, vullen en toegankelijk maken van benchmarkingdatabases. Zo beschikt Andersen Consulting over een uitgebreide set van benchmarkinggegevens met betrekking tot energiedistributie-organisaties ( $\mathrm{V}$ an der Spek en Van 't Noordende, 1996).

\section{Onderscheid met reguliere benchmarking}

Het grote verschil met reguliere benchmarking is dat van een zelfstandig uitvoeren van het benchmarkingproces geen sprake meer is. In termen van het tien-stappenplan uit figuur 1 worden bij database-benchmarking de eerste vier stappen uitbesteed. De selectie van het benchmarkingonderwerp (stap 1) wordt gedaan door de intermediair. Met behulp van inzicht in, en kennis van de markt maakt de intermediair een inschat- 
ting van de behoefte aan bepaalde benchmarkinginformatie. Het is afhankelijk van de betreffende organisatie of de benchmarkinginformatie een directe bijdrage kan leveren aan het behouden of verkrijgen van verdedigbare concurrentievoordelen. Het selecteren van geschikte benchmarkingpartners (stap 2) is een tijdrovend onderdeel van benchmarking. Uitgebreide bestudering van verschillende bronnen moet duidelijk maken welke organisaties excelleren op een bepaald gebied. Bij database-benchmarking gebeurt de selectie op een minder intensieve en gedetailleerde wijze. Een selectiecriterium is dan bijvoorbeeld de grootte van een organisatie of de branche. Bij het bepalen van de methode van gegevensverzameling (stap 3) is een belangrijke overweging hoe bewerkelijk de verschillende methoden zijn. Immers de aanleiding voor het ontstaan van database-benchmarking wordt gevormd door de minder grote tijdsinspanningen en lagere kosten. Vaak worden dan ook standaard vragenlijsten gebruikt. Tot slot geschiedt het bepalen van de prestatiekloof (stap 4) bij database-benchmarking op een gestandaardiseerde wijze. Achteraf kan wel aanleiding bestaan voor verder onderzoek en een meer diepgaande analyse.

Een aantrekkelijk aspect van databasebenchmarking is dat het een voorzichtige kennismaking met de benchmarkingmethode biedt (zie tabel 6). Een organisatie raakt bewust van niet vermoede verbeteringsmogelijkheden waardoor een beter beeld ontstaat van de behoeften en kansen voor verdergaande benchmarkingactiviteiten. Het gebruik van standaard vragenlijsten zorgt ervoor dat de informatieverzameling op een eenvoudige en efficiënte manier uitgevoerd (De Vriend en Timmerman, 1995). Daarnaast maakt het toegankelijk opslaan van gegevens in een database het mogelijk op eenvoudige en snelle wijze gegevens op te vragen voor het maken van vergelijkingen.

Tabel 6: De voordelen en nadelen van database-benchmarking

\begin{tabular}{|l|l|}
\hline Voordelen & Nadelen \\
\hline Aanzet tot verdergaande benchmarking & Geen maatwerk \\
\hline Relatief weinig tijdsbelasting en kosten & Mogelijke activering weerstand \\
\hline Bewustwording belang procesbenadering & Opgeslagen gegevens verouderen \\
\hline $\begin{array}{l}\text { Verkrijgen externe focus om eigen positie } \\
\text { te bepalen }\end{array}$ & $\begin{array}{l}\text { Achterhalen betrouwbare } \\
\text { gegevens is moeilijk }\end{array}$ \\
\hline Bieden van objectief referentiepunt & $\begin{array}{l}\text { Niet geschikt voor generieke } \\
\text { vergelijkingen }\end{array}$ \\
\hline
\end{tabular}

Minder sterke kanten aan database-benchmarking zijn dat standaardisatie tegelijkertijd maatwerk bemoeilijkt. De informatie is minder gedetailleerd, zodat de kans kleiner is dat baanbrekende ontdekkingen worden gedaan. Daarnaast bestaat het gevaar dat als gevolg van het ontbreken van een zelfstandig uitvoeren van het benchmarkingproces het 'not-invented-here'syndroom zich gaat voordoen. De aanbevelingen van de intermediair roepen dan eerder weerstand op dan dat krachten voor veranderingen worden gemobiliseerd (Zairi en Hutton, 1995). Bovendien kunnen nieuwe ontwikkelingen de opgeslagen gegevens doen verouderen. Periodiek dienen de gegevens in de database daarom te worden ververst. Een vierde nadeel is dat het in de praktijk lastig blijkt de benodigde gegevens te verzamelen. Organisaties dienen behoorlijke inspanningen te verrichten voor het opleveren van de gevraagde gegevens. Door de lage betrokkenheid bij het benchmarkingproces is de bereidheid hiertoe niet altijd even hoog. Bij geanonimiseerde vragenlijsten is bovendien achteraf de betrouwbaarheid van de gegevens nauwelijks te bepalen. Ten slotte vinden de vergelijkingen plaats op basis van een procesmodel om de prestaties en werkmethoden van organisaties onderling vergelijkbaar te maken. Dit is alleen mogelijk wanneer een hoger abstractieniveau wordt gehanteerd, waardoor het toepassen van generieke benchmarking lastig wordt (Zairi en Hutton, 1995).

\section{Conclusie}

Mede onder invloed van ontwikkelingen in de externe omgeving zijn organisaties de afgelopen jaren in toenemende mate gebruik gaan maken van benchmarking. Tegelijkertijd heeft een verdere professionalisering van de benchmarkingmethode plaatsgevonden. Dit artikel geeft een overzicht van de mogelijkheden van benchmarking om invulling te geven aan "het leren door organisaties'. Eerst hebben we stilgestaan bij wat benchmarking is en daarna bij hoe benchmarking wordt uitgevoerd. Het grootste voordeel van benchmarking is dat zij fungeert als een continue katalysator voor het leerproces binnen een organisatie. Hierbij staat het realiseren van concrete, waardevolle veranderingen voorop. Verder helpt benchmarking een organisatie een objectief beeld van de interne en externe omgeving te krijgen om vervolgens te gaan vergelijken en nieuwe, creatie- 
ve ideëen te zoeken. De bsperkingen van benchmarking liggen met name in het feit dat de uitvoering vaak een kostbare en tijdrovende aangelegenheid is.

Zoals we in dit artikel duidelijk hebben gemaakt, wordt de term 'benchmarking' gebruikt als overhoepelende term voor een heel scala aan soorten bedrijfsvergelijkingen. Afhankelijk van het onderwerp, het organisatorische niveau en de gemaakte partnerkeuze zijn een groot aantal verschillende vormen van benchmarking onderscheiden. De bestaande onzekerheid ontrent de kosten en baten van benchmarking heeft geleid tot het ontslatan van een volgende vorm valn benchmarking: database-benchmarking. Het gaat bij database-benchmarking om het vergelijken van prestaties en onderliggende werkmethoden van een organisatie met in een database opgeslagen gegevens van andere organisaties. Het is een exploratieve vorm van informatieverzameling die een bedrijf meer zekerheid geelt over de voor-en nadelen van benchmarking.

Uit onderzoek blijkı dat organisaties van plan zijn meer gebruik te maken van de benchmarkingmethode. Hiervoor bestaan een aantal redenen. Door de snelle opeenvolging van technologische ontwikkelingen zullen de gebruikte technologieën tussen organisaties meer en meer uiteen gaan lopen. Er valt dus steeds meer te leren van elkatr. Innovalies in de informaticverwerking zullen de kosten van benchmarking verder laten dalen. Een verdere toename van de (mondiale) concurrenticdruk dwingt organisaties actief te zoeken naar verbeteringsmogelijkheden en leerkansen direct te benutten. Tegelijkertijd wordt het met behulp van database-benchmarking mogelijk meer inzicht te krijgen in de potentiële kosten en baten van een regulier benchmarkingonderzoek.

Concluderend kunnen we stellen dat benchmarking kan worden gezien als een belangrijke katalysator voor (verdere) leer- en verbeteringsactiviteiten in een organisatie. Hiervoor dient wel te zijn voldaan aan enkele randvoorwaarden. Verder is het belangrijk te realiseren dat benchmarking een instrument is dat binnen een groter geheel geplaitst dient te worden. Benchmarking kan een nuttige bijdrage leveren vanuit het bestaande kader aan leer-en verbeteractiviteiten, zoals het concept van de "lerende organisatie" en Total Quality Management. Database-benchmarking kan dalarbij worden gezien als eerste stap op weg niar reguliere benchmarking en als een manter om het inzicht in de kosten en baten van benchmarking te vergroten.

\section{I T E R A T U U R}

Besterfield, Dale H., (1995), Total quality management, Prentice Hall, Englewood Cliffs, N.J.

Buzzell, Robert D. en Bradley T. Gale, (1987), The PIMS principles: linking strategy to performance, Free Press, New York.

Camp, R.C., (1992), Benchmarking: het zoeken naar de beste werkmethoden die leiden tot superieure prestaties, Kluwer, Deventer.

Clayton, T., B. Luchs, (1994), Strategic benchmarking at ICI fibres, Long Range Planning, 27 (3), pp. 54-63.

Czuchry, A.J., M.M. Yasin, J.J. Dorsch, (1995), A review of benchmarking literature: A proposed model for implementation, International Journal of Materials and Product Technology, $10(1-2)$, pp. 27-45

DeToro, I., (1995), The 10 Pitfalls of Benchmarking, Quality Progress, 28 (1), pp. 61-64.

Elnathan, D., O. Kim, (1995), Partner selection and group information in cooperative benchmarking, Journal of Accounting \& Economics, 19 (2-3), pp. 345-364.

Fitz, J., (1994), Maak ook in uw bedrijf benchmarking effectief, HRM Select, nr.3, pp. 72-87

Garvin, D.A., (1995), Leveraging Processes for Strategic advantage: a round table with Xerox's Allaire, USAA's Herres, Smithkline Beecham's Leschly and Pepsi's Weatherup, Harvard Business Review, 73 (5), pp. 76-92

Geus, A. de, (1988), Harvard Business Review, March-April.

Goldwasser, C., (1995), Benchmarking: People make the process, Management Review, June, pp. 39-43

Hamel, G., A. Heene, (1994), Competence-based competition, John Wiley, Chichester.

Hamel, Gary en C.K. Prahalad, (1994), Competing for the future, Harvard Business School Press, Boston, MA.

Kanji, Gopal K. en Mike Asher, (1996), 100 methods for total quality management, Sage, London.

Lewis, J.C., M.M. Naim, (1995), Benchmarking of aftermarket supply chains, Production Planning and Control, 6 (3), pp. 258-269.

Lucertini, M., F. Nicole, D. Telman, (1995), Integration of Benchmarking and Benchmarking of Integration, International Journal of Production Economics, 38 (1), pp. 59-72.

Kanter, R.M., (1989), Als reuzen leren dansen: management, strategie en carrière in de jaren negentıg... een nieuwe uitdaging, Scriptum, Schiedam.

NIPO, (1994), Management samenvatting 'Onderzoek naar het gebruik van benchmarking in Nederland'. 
Noordende, S. van 't, en T. van der Spek, (1996), Benchmarking bij financiële instellingen: Een kijkje in de keuken van de concurrent, Banking Review, april, pp. 39-42.

Pedler, M., J. Burgoyne, T. Boydell, (1991), The learning company: a strategy for sustainable development, McGraw-Hill, London.

Pegels, C. Carl, (1995), Total quality management: a survey of its important aspects, Boyd \& Fraser Publishing Company, Danvers, Mass.

Pryor, L.S., S.J. Katz, (1993), How benchmarking goes wrong (and how to do it right), Planning Review, 21(1), pp. 6-11.

Rolstaadas, A., (1995), Benchmarking: theory and practice, Chapman \& Hall, London.

Schramade, P.W.J., S. Tjepkema, (1993), Benchmarking bij AT\&T - Een gerichte manier om als organisatie te leren van anderen, Opleiding en Ontwikkeling, 6 (6), pp. 15-20.

Senge, Peter M., (1990), The fifth discipline: the art and practice of the learning organization, Doubleday, New York.

Senge, Peter M., (1994), The Fifth Discipline Fieldbook: strategies and tools for building a learning organization, Currency, New York.

Shetty, Y.K., (1993), Topprestaties door benchmarking, HRM Select, nr.3, pp. 14-23.

Spendolini, M.J., (1992), The Benchmarking book, Amion, New York.
Voort, L.P.F. van de, J.M. de Vries, (1993), Benchmarking doorbreekt de bijziendheid van een organisatie, Kwaliteit in Bedriif, juli/augustus, pp. 4-8.

Voort, L.P.F. van de, J.M. de Vries, (1993), Benchmarking in de praktijk: Eenvoudig concept, moeilijke uitvoering, Kwaliteit in Bedriif, september/oktober, pp. 20-25.

Voort, L.P.F. van de, J.M. de Vries, (1994), Benchmarking: Het benutten van een leerhouding, TaC, nr. 7/8, pp. 20-25.

Vriend, G.K. de, A. Timmerman, (1995), Benchmarking: een strategie om concurrentievoordeel te behalen, Kluwer. Deventer.

Vries, J.M. de, J.J.W. van der Togt, (1995), Benchmarking in 9 stappen: leidraad voor de praktijk, Kluwer, Deventer.

Waalewijn, Ph., en B.W.C.M. Kamp, (1994), Strategische Benchmarking; discussienota Rotterdams Instituut voor Bedriffseconomische Studies, januari.

Weber, J., M. Hamprecht, H. Goedel, (1995), Benchmarking van de controllersfunctie, Financieel Management Select, 5 (3), pp. 28-41.

Winkler, M.C.E., (1996), Benchmarking van benchmarkingorganisaties, NGI Magazine, jrg. 11, 11 (november), pp. 12-20.

Zairi, M., R. Hutton, (1995), Should you use benchmarking databases?, Technology Strategies, April, pp. 18-19.

Zairi, M., P. Leonard, (1994), Practical benchmarking: the complete guide, Chapman \& Hall, London. 